\title{
Outdoor Space Analysis and Thinking in Old Urban Residential Area Under the Goal of Healthy Settlements
}

\author{
$\mathrm{QinYu}^{1 *}$ \\ ${ }^{1}$ School of Construction Engineering, Kunming University, Kunming, Yunnan 650214, China \\ *Corresponding author. Email: qinyu100@outlook.com
}

\begin{abstract}
The health problem has always been the most basic and important survival problem related to human society. More and more chronic diseases and unexpected public health incidents remind people whether the health of urban living environment needs attention. As a large and densely populated living place in the city, the living environment of the old urban district needs to be improved. Based on the theoretical research, this paper analyzes the characteristics and concepts of healthy settlements, and then combined with the field investigation, the outdoor space of the old urban district is deeply investigated and analyzed. Finally, some suggestions for the outdoor space reconstruction of the old district are put forward. The research aims to provide more thinking and help for the upgrading of the old district.
\end{abstract}

Keywords: health, healthy settlements, old urban residential area, outdoor space, reform proposal

\section{INTRODUCTION}

Health, an eternal theme of human survival, has always attracted much attention. When the human society entered the industrial revolution, the urban population surged, the ecological environment deteriorated, various infectious diseases were frequent, and health problems were threatened unprecedentedly. Many diseases have killed tens of thousands of people, such as early British cholera, American yellow fever, Spanish flu and so on, social public health and the safety of the living environment are seriously affected. However, this sudden infectious disease has not passed away with the development of the times. Looking back over the last 20 years, massive human epidemic are still erupted around the world unscheduled. In 2003, SARS outbreak in China lasted more than half a year, Guangzhou, Beijing and Hong Kong have become major disaster areas. Mexico's influenza A (H1N1) pandemic in 2009, Ebola epidemic in 2014 across Africa. And at the end of 2019, a new type of coronavirus-infected pneumonia found in Wuhan, China, more than 10,000 people have been diagnosed throughout the country in just one month, and there have been cases of infection in several countries around the world. This sudden public health incident has once again sent China and the world into a panic.

In addition to the serious impact of major infectious diseases on human health, a growing variety of daily chronic and psychological diseases have become important factors affecting human health, such as cardiovascular and cerebrovascular diseases, diabetes, obesity, chronic respiratory diseases, and malignant tumors, depression, etc., have become the leading killer of human health. Most of these diseases are caused by lack of exercise, discomfort, air pollution and depression.[1]

In terms of China's urbanization development, by the end of
2019, the national urbanization rate had reached $60.60 \%$ [2], it means that more than $60 \%$ of the population lived in the city. With the continuous development of social economy, the quality of urban habitat environment is increasingly valued. To enable urban people to live a healthy life is the primary task and construction goal of every city in every country. In 2015, General Secretary $\mathrm{Xi}$ Jinping mentioned that "It is necessary to always put the health and safety of the broad masses of the people at the forefront of efforts to effectively prevent and control infectious diseases and respond to public health emergencies."[3] In August 2016, at the National Health and Health Assembly, he added that "without universal health, there would be no overall well-off", "People's health should be placed as a strategic priority for development ".[4]

As the main living place and space carrier of urban residents, the health of settlements is closely related to the safety of people's residence and physical and mental health, and also to the sustainable development of social economy. So what is a healthy settlement?

\section{CONCEPT AND EVALUATION BASIS OF HEALTHY SETTLEMENTS}

To define the concept of healthy settlements clearly, we must understand the meaning of "health " first. Traditionally, health is generally understood as the health of an individual without disease, but in fact health is not limited to the physiological state of the individual. In 1948, the World Health Organization's definition of health was considered a modern and relatively complete scientific concept of health, that is, health not only refers to a person without illness or weakness, but also refers to a kind of physical, psychological and social state of perfection.[5] This statement emphasizes the 
comprehensiveness of health, health-or-not needs to be judged from physical, psychological and social dimensions. In-depth analysis, that means whether there are organic and functional diseases, whether there are psychological pessimism and depression and other negative emotions, and whether there is violation of social ethics, contrary to the public recognition of the phenomenon of behavior.

WHO also described "healthy cities" in 1994, and in 1996 set out 10 specific criteria for healthy cities.[6] To sum up, it contains the following principles: The first is, the principle of sustainability, that is to meet the needs of contemporary people without harming the interests of future generations; The second is, the principle of equality, namely, the right of everyone to health and resources; The third is, the principle of harmony, which is to promote economic and social ecology and other aspects of harmonious symbiosis and interactive communication.

Reference to the definition of healthy and healthy cities, healthy settlements should also be analyzed and measured from multiple perspectives. First of all, in terms of demand, healthy settlements should meet the needs of people in three aspects, they are: physical health needs, mental health needs and social interaction needs. Among them, physical health needs are the most basic health needs, that is, physical health without disease; Mental health needs often refer to the positive and optimistic psychological characteristics of people, no depression, no despair, which is also an important aspect of health, sometimes even more important than physical health. Social communication needs, are higher requirements which generally based on the physical and mental health, that is the desire to maintain good contact with the community, to have more social resources, and to get social attention and recognition.

Combined with the above three needs, healthy settlements should be judged on the following three levels. Firstly, at the material dimension, healthy settlements should meet the principle of environmental ecology and sustainability. Secondly, at the spiritual dimension, healthy settlements should promote a positive, optimistic, equal and friendly atmosphere for the population. Thirdly, at the social dimension, healthy settlements should always have easy contact with the outside world, and could gain more social recognition through good group spirit. As shown in Figure 1.

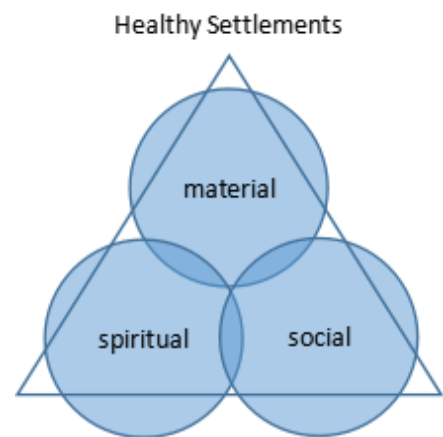

Figure 1 Chart of Healthy Settlements

Based on the above analysis, healthy settlements can be understood as: A kind of human living place with ecological and sustainable material space environment, positive and friendly spiritual space environment and convenient and harmonious social relationship environment.

\section{OUTDOOR SPACE DESIGN REQUIREMENTS FOR HEALTHY SETTLEMENTS}

According to the concept and evaluation principle of healthy settlements, its outdoor space design needs to meet the requirements of material environment and human environment.

\subsection{Physical and Environmental Dimensions}

(1) Reasonable layout

From the point of view of planning and design, healthy settlements should have a clear spatial structure and reasonable spatial layout. In structure, there is a clear sense of spatial structure system and spatial order; In form, point, line, surface combination, open and introverted combination; In distribution, outdoor activities should be properly dispersed to avoid excessive concentration, moreover, the service radius and access distance of each space are controlled reasonably.

(2) Perfect function

The residential area is an important living place for residents'daily living, leisure and entertainment, therefore, its outdoor space should have perfect substantive function. From leisure facilities, recreational facilities, recreational facilities to commercial service facilities, etc., which are closely related to daily life, let residents meet the needs of daily life within the scope of community space.

(3) Suitable scale

Spatial scale is directly related to the function and experience of space, designing different scale spaces with different functional requirements, open or hidden, comfortable or oppressive. The adjustment of spatial scale contains the transformation of spatial atmosphere, it enriches the user's intuitive feeling and promotes the flexibility of space function.

(4) Various types

Outdoor spaces in healthy settlements should also meet multi-theme, multi-form requirements, combine different crowd needs, different use characteristics, and different cultural activities to set up rich and diverse spatial types. For example, a Children's Paradise for children, an Elder Space for the elderly, an Art Stage for the art lovers, or a relatively independent and quiet reading corner, to enrich the space type and improve the connotation attraction of the space place by setting the space theme.

\subsection{Human Environmental Dimensions}

(1) Safety and Pleasure

The sense of security is the most basic human need, and 
the sense of pleasure is the feeling of pleasure after satisfying the sense of security. The healthy community should first meet the requirements of community residents'safety and pleasure from the aspect of human environment, that is, to ensure the safety and pleasure of living and living. The safety of space design includes the security of physical environment and the sense of psychological and emotional security. The safety of the environment should be checked in terms of ergonomics and related design specifications, and the psychological sense of security is the psychological implication of the surrounding environment to people. For example, too dark a space for fear and depression, too focused a space for tension, anxiety, and remote and hidden places can be a corner of the dirt.

The pleasure can come from the excellent landscape quality, the perfect recreation and leisure facilities, the good interpersonal relationship, and the rich content of sports activities, etc. Through planning design and organizational management to promote the improvement of related aspects, will play a positive role in the promotion of residential pleasure.

\section{(2) Quality and Sharing}

Because of the residential outdoor activities and facilities belonging to the residents of public activity space, these resources should be allocated in a rational and balanced manner from the perspective of planning and design, based on the principle of equal sharing. It need to avoid uneven spatial distribution and unbalanced facilities, as far as possible to ensure that every group of people can find a suitable space for their own areas, every resident in the objective equal rights treatment.

(3) Care Mutual Assistance

Besides the excellent quality of space environment, the inner community spirit and interpersonal relationship are also very important. In the planning and design of settlements, the communication between people can be promoted through the creation of communication and display space; To promote the development and wide participation of community activities through the construction of open and open space; At the same time, it can also consciously provide help to the elderly and weak groups in the allocation of facilities, and guide the formation of a caring and mutual community spirit atmosphere.

\section{OUTDOOR SPACE CASE INVESTIGATION IN OLD URBAN DISTRICT}

As of July 2019, the State Ministry of Housing announced that the country reported 170,000 old residential areas in cities and towns in need of renovation, involving hundreds of millions of residents.[7] It can be seen that the renovation of the old residential area is a huge, urgent to be solved, related to hundreds of millions of people an important project. On December 25, 2019, the Kunming Municipal Housing Bureau issued A Statement On the Renovation of the Old Urban District in Kunming in 2019. The task of rebuilding the old urban district in Kunming is 179 residential areas, involving an area of 2.633 million square meters and 31551 households.

In this study, three representative old district in Kunming (Fengning district, Chunhui district, Lingjiaotang district) were selected as the survey objects. These three communities were built in the early 1990s, with more than a thousand households and relatively large settlements. Among them, there are 7100 households in Fengning District,75 residential buildings, more than 20,000 people, the current rental rate is nearly $50 \%$. Chunhui District, the three phases of a total of 4400 households, more than 10,000 people. Lingjiaotang District, previously divided into the east, south and northwest five districts, since the demolition requisition in 2007, only the East, Central, North District left, the existing households are $1200+$.

This survey mainly adopts the questionnaire interview and the field survey, emphatically understands the residents' satisfaction to the residential area, collects the present situation question, and collects the settlement space transformation opinion and so on.

In August 2019, the research team distributed 100 questionnaires to the residents of Fengning District, Chunhui District and Lingjiaotang District in Kunming, with a total of 300 questionnaires, and 289 valid answers received, accounting for $96.3 \%$. Among the respondents, $48 \%$ were men, $52 \%$ were women, $22.1 \%$ were aged $20-39,30.6 \%$ were aged $40-59$ and $47.3 \%$ were over 60 . As shown in Figure 2.

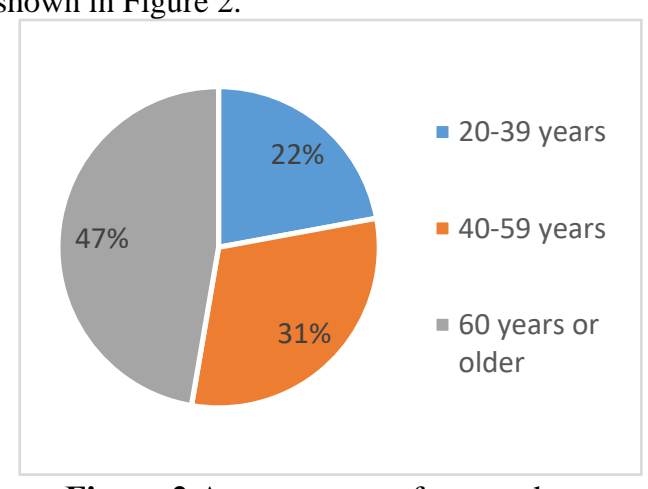

Figure 2 Age structure of respondents

The main contents of the questionnaire include:1) The satisfaction evaluation of the outdoor space environment of the residential district, 2) Residents' Daily Habits and Living Conditions 3) The requirements of the ideal outdoor Space environment, 4) The content of the most desired rectification for the outdoor space.

In this survey, in the part of the outdoor space satisfaction of the residential area, the questionnaire showed that the overall satisfaction of the residents was not high. As shown in Figure 3. 


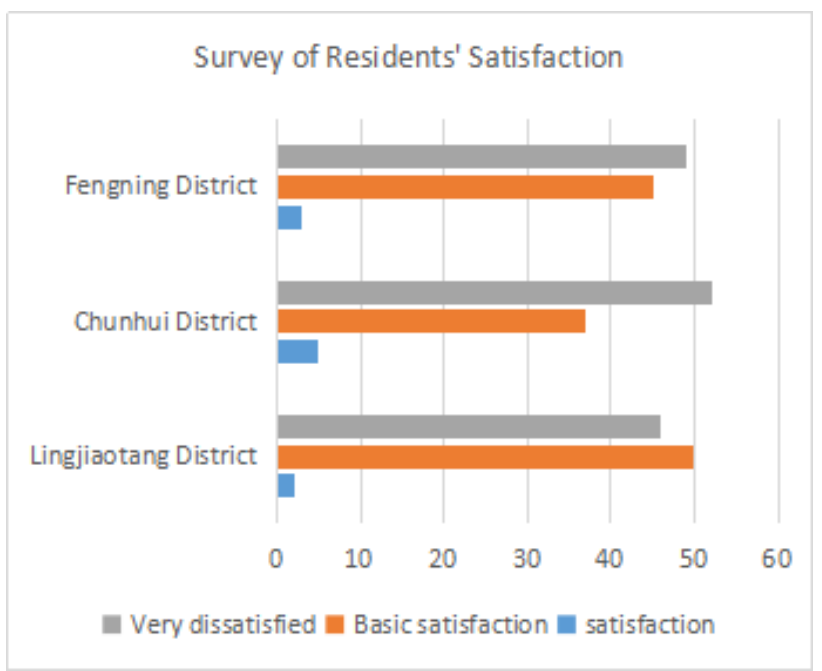

Figure 3 Survey of Residents' Satisfaction

The three most unsatisfactory areas were: sanitary environment, leisure facilities and exercise yard. In the understanding of the interviewee's daily life habits and living conditions, it was found that "feeling lost, lonely, helpless" unexpectedly accounted for $21 \%$. In the collection of opinions on the ideal outdoor space environment, the first three characteristics of the indicators most concerned by the residents are: Beautiful environment, Perfect facilities and Care for the old and the weak. In addition, in the collection of opinions on the rectification of outdoor space in residential areas, the three items that residents most wish to rectify are: To improve the Green landscape, To add the leisure facilities, To care for vulnerable groups. As shown in Table 1.

Table 1 Results of the Residents' Willingness Survey

\begin{tabular}{|c|c|}
\hline $\begin{array}{c}\text { Contents of the } \\
\text { investigation }\end{array}$ & $\begin{array}{c}\text { The top three items in the } \\
\text { statistics }\end{array}$ \\
\hline $\begin{array}{c}\text { The most unsatisfactory } \\
\text { aspects }\end{array}$ & Sanitary environment \\
\cline { 2 - 2 } & Leisure facilities \\
\cline { 2 - 2 } $\begin{array}{c}\text { Ideal Residential Outdoor } \\
\text { Space Environment } \\
\text { Requirements }\end{array}$ & Beautiful environment \\
\cline { 2 - 2 } $\begin{array}{c}\text { The most desirable to be } \\
\text { rectified }\end{array}$ & Perfect facilities \\
\cline { 2 - 2 } & Improving green landscape \\
\cline { 2 - 2 } & Increasing leisure facilities \\
\cline { 2 - 2 } & Caring for vulnerable groups \\
\hline
\end{tabular}

The data collected in this survey, to some extent, reflects the current situation of outdoor space in old urban areas and the will of the people, meanwhile provides ideas for the next step of rectification.

\section{SUGGESTIONS FOR RECTIFICATION OF OUTDOOR SPACE IN OLD DISTRICT}

In view of the common problems existing in the outdoor space environment of the old urban district, taking the healthy residential area as the construction goal, considering the material and human dimension requirements comprehensively, the following five rectification suggestions are put forward from the perspective of planning and design:

\subsection{Enhancing Space Function and Improving Service Facilities}

Function is an important intrinsic element under the form of space, which embodies the substantive meaning of space existence. The outdoor space of the old district either has no definite function orientation, the type is monotonous, the content is empty, or be abandoned or changed in the later use management process, or have lost their due function because of the original facilities in disrepair.

First of all, it is suggested that the function orientation should be clearly defined, the function use should be allocated reasonably, and the function and theme of the space should be highlighted. Secondly, it promotes multi-purpose superposition, multi-function integration, and introduces functional composite outdoor space, thus improving the utilization rate of space. Moreover, combined with a functional location. For example, the leisure communication space can arrange more leisure seats, add sun shelter roof to improve space comfort and increase use time; Sports fitness space, should be equipped with different types of sports facilities for people to provide fitness and entertainment conditions; Cultural entertainment space, can be set up some interesting, participatory activity facilities; Publicity display space, can be combined with road, square, green, landscape design, through different publicity and display forms to achieve the role of publicity, display, education, beautification.

\subsection{Improving Space Quality and Landscape Image}

Space quality is determined by the nature of space, structure distribution and landscape image. On the one side, different locations, different types and different properties of outdoor space, its spatial characteristics should have obvious differentiation. The outdoor space of the old district often lacks the marking because there is no prominent characteristic. On the other side, the space is defined by the outer entity around the formation of a specific place, with a clear sense of the space field, many outdoor spaces of the old district are made definition fuzzy and felt bad, because of the backward design 
techniques and limited use of materials.

It is suggested to improve the image of the outdoor space environment according to the nature of space, showing different spatial characteristics. Including: adding iconic landscape elements, highlighting important spatial nodes, improving spatial identity and appreciation; Optimization of the form of space limit, the use of material, color, height difference and other spatial definition to strengthen the sense of space experience; Attaching importance to the space aesthetics design, improve the quality of space landscape.

\subsection{Integrating Space Layout to Guide Leisure Health}

The spatial layout often represents the structural relationship of the outdoor space in the residential area, the ideal spatial layout should have clear structure, reasonable distribution, combination of concentration and dispersion, and combination of dynamic and static. The type and function of outdoor space in old district are single, and often be set in a certain area, the distribution is not balanced.

The imbalance of spatial distribution is not only not conducive to the equal sharing of facilities resources, but also too concentrated space site layout is very unfavorable to the protection of sudden infectious diseases. Therefore, it is suggested that the space structure should be adjusted properly in the renovation of the old residential area, and some unused and abandoned scattered space and corner space should be sorted out and reused, to guide the crowd to achieve "small concentration, large dispersion ", and ensure good ventilation and sufficient sunshine, so as to achieve residents'outdoor leisure health.

\subsection{Enriching the Green Plant Level and Improving the Ecological Environment}

Greening vegetation is an important aspect of beautifying community environment, purifying air quality and regulating regional microclimate. Old communities usually have fewer green areas, and green plants are monotonous. In addition to the maintenance work is not in place, many old areas of vegetation is sparse and messy, not only did it not play the role of beautifying the environment, but instead became a place where garbage and debris were stacked.

It is suggested to supplement and repair the green planting in the district. On the one hand, according to the climate characteristics of the region, select suitable and healthy plant species for planting. As far as possible to achieve four seasons evergreen, alternate blooming, high and short collocation, far and near uneven. On the other hand, green planting can be extended from plane to stereo, to use outdoor rest pavilions, corridors, terraces and other facilities to increase vertical greening landscape, enrich the greening level. A good green environment not only gives people a pleasant feeling, but also improves the ecological environment and regulates the microclimate of residential areas. It is a good place for people to cool off after dinner, it allows people to have the will to get close to them, can promote walking and communication, stimulate life enthusiasm, and contribute to physical and mental health.

\subsection{Supplying Special Facilities to Care For Vulnerable Groups}

Healthy settlements, in addition to the beautiful environment, well-equipped, but also reflected in humanistic care and inner spirit. Old communities are mostly aging communities, and most of the residents are elderly people, some of them have difficulty in moving, living alone and lonely. Outdoor space needs to take full account of the physical and psychological needs of the elderly, from the perspective of space design to facilitate its travel, promote its activities, guide its participation. In the transformation, first, it is suggested to increase barrier-free design to meet the accessibility of outdoor space. The second is to provide suitable space for the activities of the elderly, such as fitness activity space for Taijiquan and square dance, entertainment and leisure space for chess and mahjong, a circular walkway for walk slowly, and so on. In addition, there are often more places for the elderly to live in preschool children, and the outdoor space of the community needs to explore open places for children to play and easy to care for.

\section{SUMMARY}

Healthy settlements are sustainable urban human settlements goals based on current urban social health concerns, it explained the positive healthy life idea from the material level, the spiritual level and the social level. The old residential areas in the city, because of the wide distribution of quantity, poor environmental quality, strong residents response and other problems, urgently need to get more attention and improvement. This study starts with theoretical analysis and field research, through analyzing the needs of healthy settlements, to summarize and put forward some suggestions for the rectification of outdoor space in the old district from the angle of material space and human spirit.

But it is only a strategy based on planning and design, the old district's rectification work involves a wide range of complex problems, it needs all sectors of society to work together and coordinate with each other to promote the quality of space environment in old urban areas.

\section{REFERENCES}

[1] Fan Xudong, International Research Review and Construction Enlightenment of Healthy City, Bulletin of Sport Science \& Technology, 26(10) (2018)28+70. DOI: https://doi.org/10.19379/j.cnki.issn.1005-0256.2018.1 0.011 
[2] http://www.stats.gov.cn/tjsj/zxfb/202001/t20200117_ 1723383.html

[3] http://www.chinanews.com/m/gn/2015/11-25/764135 4.shtml

[4] https://www.cn-healthcare.com/article/20161121/wap -content-487400.html
[5] Zhang Tianyao, The Theoretical Framework Of Healthy City Planning From Ecological Viewpoint, Planners, 31(06)(2015)20-26

[6] DOI:https://doi.org/10.19694/j.cnki.issn2095-2457 .2014 .25 .117

[7] https://ra.mbd.baidu.com/5cuql72?f=cp\&u=5364b $5032 \mathrm{~d} 353720$ 